\title{
Power Quality Impacts in a Typical Microgrid
}

\author{
Arangarajan Vinayagam ${ }^{1}$, Asma Aziz $^{1}, \mathrm{KSV} \mathrm{Swarna}^{1}$, Suiyang Khoo ${ }^{1}$ and Alex Stojcevski ${ }^{2}$ \\ ${ }^{1}$ Faculty of Science, Engineering and Built Environment, Deakin University, Geelong-Australia \\ ${ }^{2}$ Centre of Technology, RMIT University, Vietnam
}

\begin{abstract}
Microgrid (MG) power system plays an important role to fulfill reliable and secure energy supply to critical loads of communities as well as for communities in remote area. Distributed Generation (DG) sources integrated in a MG provides numerous benefits, at the same time leads to power quality issues in the MG power distribution network. Power Quality (PQ) issue arises due to the integration of an intermittent nature of Renewable Energy (RE) sources with advanced Power Electronics (PE) converter technology. Also, presence of nonlinear and unbalancing loads in MG seems to affect $P Q$ of the energy supply in power distribution network. In this paper, PQ impacts like; power variation, voltage variation, Total Harmonic Distortion (THD), and Unbalance voltage level have been analysed in Low Voltage (LV) distribution network of typical MG power system model. In this study, development of MG model and PQ impact analysis through simulation has been done in PSS-Sincal software environment. Analysis results from the study can be used as a guideline for developing a real and independent MG power system with improved PQ conditions.
\end{abstract}

Keywords-microgrid; distributed generation; power quality; renewable energy; power electronics

\section{INTRODUCTION}

A small entity of electrical network known as Microgrid provides secure and reliable energy supply to the critical loads of communities. It also provides a sustainable and selfdependent energy supply to communities in remote area where there is no access or facility for main grid power system. MG should be capable of operating either in on-gird or off-grid mode $[1,2]$. MG incorporates several DG sources like; RE, conventional power units, and various types of energy storage options. DG in MG provides several benefits such as; low carbon emission of energy supply, improved efficiency and reliability of energy supply, reduction of power losses in distribution network, and defers enhancement of distribution network infrastructure facility etc. Despite of benefits, DG also creates various PQ issues like; power flow variation which causes voltage and frequency deviations, unbalance voltage and current, poor power factor, harmonic distortions, voltage flicker, voltage sag / swell etc. in the MG distribution network [3, 4]. PQ analysis of MG is essential to quantify the level of PQ issues, in order to develop a real MG model with improved PQ conditions through optimum control measures. Several studies and analysis were carried out by researchers over the PQ issues in MG power network at various conditions. [5] THD analysis was performed through simulation in a typical Photo Voltaic (PV) integrated low voltage distribution network at various conditions. THD voltage and current levels were found high in the following conditions; penetration of PV at higher level, far end feeder, low load, and load operates at leading power factor. [6] PQ issues were analysed in a typical MG power system at various level of RE penetrations and weather conditions through Matlab software simulation. The level of PQ issues was found high, at $66.6 \%$, and $99.9 \%$ of RE penetration as compared to $33.3 \%$ level. [7] THD analysis was done while integrating PV with linear and non-linear load. At higher PV penetration level with linear load, THD was found high. At $10 \%$ of PV penetration with non-linear load (with respect to linear load), THD was around $4 \%$ whereas at $15 \%$ of PV penetration with non-linear, THD level was found above standard limit around $5.06 \%$. In addition to THD analysis, three PQ indices were applied to evaluate level of power distortion, wave form distortion, and unbalance in the system network. Similarly, in [8] analysed at above $50 \%$ of PV penetration, voltage THD level exceeds above standard level, also found that reduction of voltage THD at worst node when penetrating more PV nearby substation as well as with more loops in highly meshed network.

In this study, in addition to THD analysis other PQ factors such as; power variation, voltage variation, unbalance voltage level also have been analysed in a typical MG power system model through software simulation. Development of MG model and impact analysis has been carried out in PSS-Sincal software environment [9]. The output results from this study will aid in developing a real MG model with improved PQ conditions for communities in future. The section II defines the details of MG model and types of analysis, section III explains the analysis results and discussion, and the conclusion of this study and future research work is given in section IV.

\section{MG MODEL AND DETAILS OF ANALYSIS}

\section{A. MG Power System Model}

Development of MG model and specification of its associated elements have been considered as follows; Grid source (100 MVA/66 KV) Solar PV (100 KW each), Diesel generator unit (3.25 MVA/2.4 KV/ power factor: 0.9), three phase linear and non-linear load groups, single phase distributed loads with single phase solar PV (10 KW each), $11 \mathrm{KV}$ feeders, main transformer ( $8 \mathrm{MVA}, 66 \mathrm{KV} / 11 \mathrm{KV})$, and 4 numbers of distribution transformers(1 MVA, $11 \mathrm{KV} / 415 \mathrm{~V})$. The details of DG units, $11 \mathrm{KV}$ line parameters, and details of each load groups are shown in Table 1, Table 2, and Table 3 respectively. The typical schematic diagram of MG model is shown in Figure 1. 


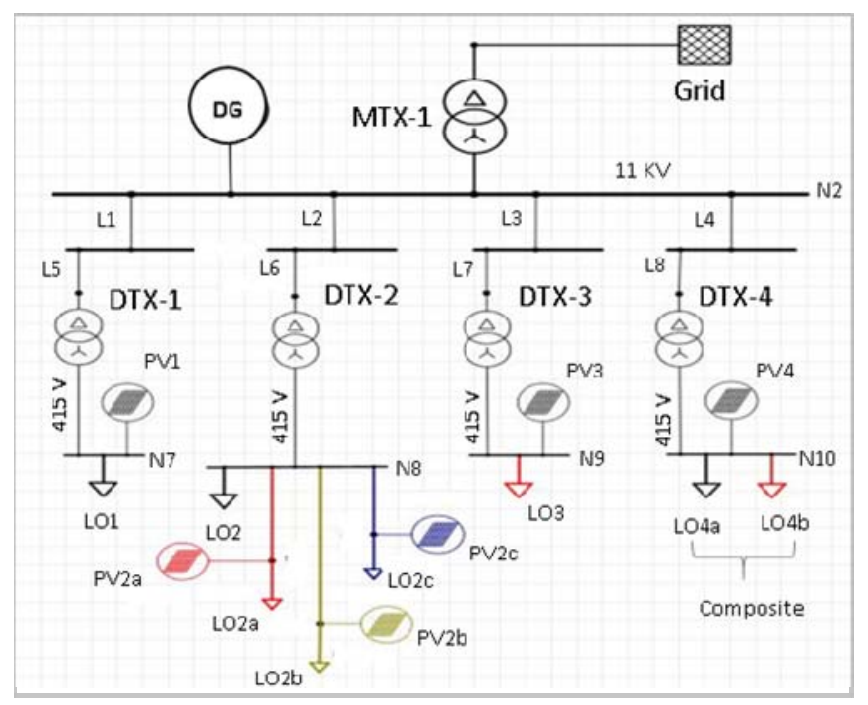

FIGURE I. TYPICAL SOLAR PV MG MODEL

TABLE I. DETAILS DG UNITS

\begin{tabular}{|c|c|c|}
\hline \multirow{2}{*}{ DG units } & \multicolumn{2}{|c|}{ Specification } \\
\cline { 2 - 3 } & Capacity & Bus Node \\
\hline Three phase Solar PV1 & $1 \mathrm{MW}$ & N7 (415 V) \\
\hline Single phase Solar PV2a $/ 2 \mathrm{~b} / 2 \mathrm{c}$ & $0.01 / 0.1 / 02 \mathrm{MW}$ & $\mathrm{N} 8(415 \mathrm{~V})$ \\
\hline Three phase Solar PV3 & $0.5 \mathrm{MW}$ & N9 (415 V) \\
\hline Three phase Solar PV4 & $1 \mathrm{MW}$ & N10 (415 V) \\
\hline Diesel Generator (DG) & $3.25 \mathrm{MVA}$ & N2 (11 KV) \\
\hline
\end{tabular}

TABLE II. 11 KV LINE PARAMETERS

\begin{tabular}{|l|c|c|}
\hline \multirow{2}{*}{\multicolumn{1}{|c|}{ Type of Load }} & \multicolumn{2}{c|}{ Load Details } \\
\cline { 2 - 3 } & MVA & Bus Node (415 $\mathbf{~}$ ) \\
\hline Linear (LO1) & 1 & N7 \\
\hline Linear (LO2) & 0.5 & N8 \\
\hline Single phase Linear (LO2a/2b/2c) & $0.3 / 01 / 0.01$ & N8 \\
\hline Linear (LO3) & 0.5 & N9 \\
\hline Linear + Non-Linear (LO4a + 4b) & $0.5+0.5$ & N10 \\
\hline
\end{tabular}

TABLE III. DETAILS OF LOAD GROUPS

\begin{tabular}{|l|c|c|c|c|c|c|c|c|}
\hline \multirow{2}{*}{ Line } & \multicolumn{7}{|c|}{ Feeder Specification } \\
\cline { 2 - 9 } & $\mathbf{L 1}$ & $\mathbf{L 2}$ & $\mathbf{L 3}$ & $\mathbf{L 4}$ & $\mathbf{L 5}$ & $\mathbf{L 6}$ & $\mathbf{L 7}$ & $\mathbf{L 8}$ \\
\hline $\begin{array}{l}\text { Length } \\
(\mathrm{Km})\end{array}$ & 0.41 & 0.34 & 0.36 & 0.40 & 0.16 & 0.16 & 0.16 & 0.16 \\
\hline \multicolumn{2}{|l|}{ Parameters / Km } & $\mathrm{R}=0.282 \Omega$ & \multicolumn{2}{|c|}{$\mathrm{X}=0.357 \Omega$} & \multicolumn{2}{c|}{$\mathrm{C}=10.5 \mathrm{nf}$} \\
\hline
\end{tabular}

\section{B. Power Flow Analysis}

Due to an intermittency nature of solar irradiance, variation of solar PV output power can be expected in different timescales such as; in seconds, minutes, and minutes to hourly level. In this study, power variation, and voltage variation level at LV local bus nodes in MG network were estimated as per daily load and solar profile condition through Newton Raphson algorithm method of power flow analysis.

\section{Harmonic Analysis}

Harmonics are the frequencies that are integer multiples of fundamental frequency. PE converter and non-linear loads are the main causes for current harmonics domination in $\mathrm{MG}$ network. Due to the system impedance, harmonic current injected into the supply system can also cause the rise of voltage harmonics. In PSS-Sincal, voltage and current THD level were estimated on the basis of network impedance between a defined starting and ending frequency at given frequency step. In addition, typical harmonic current data for PV inverter and non-linear load [10] (25\% of harmonic current level of Class-A- and Class-D equipment's) have been considered for this analysis. Typical harmonic current curves for $100 \mathrm{KW}$ PV inverter and non-linear load (Class-A and Class-D equipment's) are shown in Figure 2 and Figure 3 respectively. THD is the ratio of r.m.s value of sum of all the harmonic components up to a specific order to the r.m.s value of fundamental component. The current THD $\left(\mathrm{THD}_{\mathrm{I}}\right)$ and voltage THD $\left(\mathrm{THD}_{\mathrm{V}}\right)$ are expressed as per in the following equations (1) and (2) [11] respectively.

$$
\begin{aligned}
\mathrm{THD}_{\mathrm{I}} & =\frac{\sqrt{I_{h 2}^{2}+I_{h 3}^{2}+I_{h n}^{2}}}{I_{h 1}^{2}}(\%) \\
\mathrm{THD}_{\mathrm{V}} & =\frac{\sqrt{U_{h 2}^{2}+U_{h 3}^{2}+U_{h n}^{2}}}{U_{h 1}^{2}}(\%)
\end{aligned}
$$

where $I_{h 1}$ is the current harmonic fundamental, $U_{h 1}$ is the voltage harmonic fundamental, $\mathrm{I}_{\mathrm{hn}}$ is the highest order of current harmonic, and $U_{h n}$ is the highest order of voltage harmonic.

\section{Unbalance Voltage Analysis}

Voltage unbalance is a significant $P Q$ issue in the distribution network of MG power system. Voltage unbalance is mainly caused by uneven distribution of single phase loads, single phase DG units, and unequal system impedance in LV network etc. [12]. In PSS-Sincal software, unbalance voltage level can be calculated through the asymmetrical method of load flow analysis. For this analysis, typical unequal distribution of single phase load and single phase solar PV have been considered. Unbalance voltage factor (UVF) has been calculated as per the equation (3) [13] as shown below.

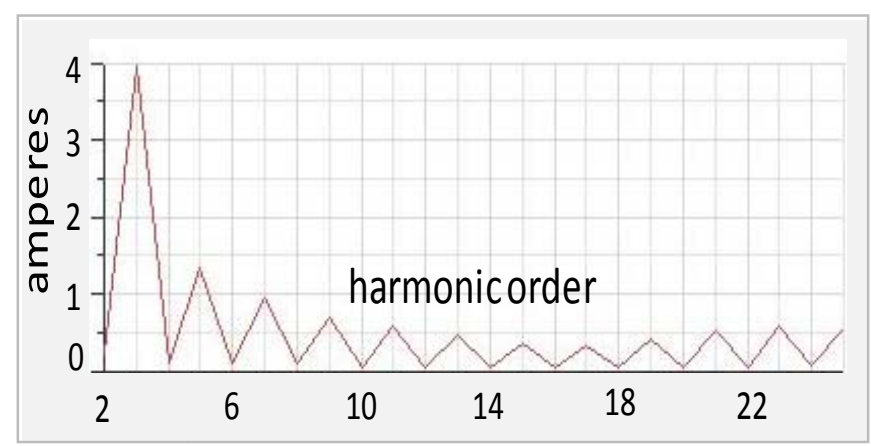

FIGURE II. HARMONIC CURRENT CURVE FOR PV INVERTER 


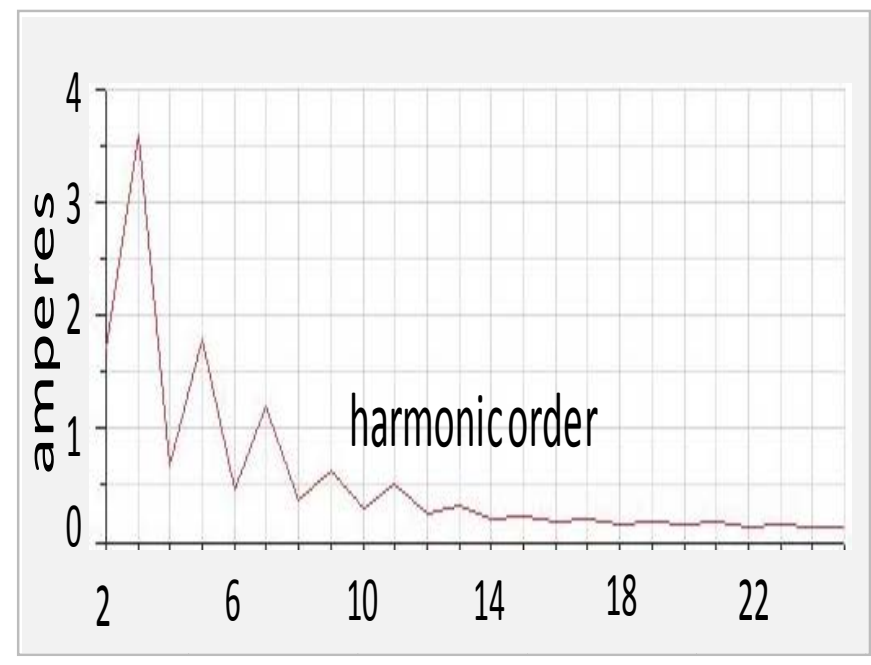

FIGURE III. HARMONIC CURRENT CURVE FOR NON-LINEAR LOAD

$$
\mathrm{UVF}=\left[\frac{\mathrm{Vn}}{\mathrm{Vp}}\right](\%)
$$

where $V_{n}$ is negative sequence voltage, $V_{p}$ is positive sequence voltage.

\section{RESULTS AND DISCUSSION}

In this section overall simulation results, given in Table 4 and Table. 5 are discussed in detail.

\section{A. Power Variation}

Solar disturbance due to the cloud effect can be considered as one of the main reason for power intermittency in PV output. PV power intermittency can be considered in different time scales like; in "second" level causes voltage flicker and in "minute" level affects the regulation of power generation reserve in power system [14]. A typical solar disturbance for each PV $(100 \mathrm{KW})$ with total installed capacity of around 1 MW, connected at LV $(415 \mathrm{~V})$ bus node N7 has been considered for this analysis. During this period of solar disturbance from 11 hours to 11:40 hours, each PV output power variation was observed from minimum $0 \mathrm{KW}$ to maximum $73 \mathrm{KW}$, as shown in Figure 4.

According to daily load profile, an active power and reactive power flow from supply sources (Grid / Diesel generator) are shown in Figure 5. Due to this cumulative effect of power variation from all ten PV units, corresponding power flow variation from grid supply source and diesel generator unit were observed during on-grid and off-grid mode of operation. As shown in Figure 6, power variation was observed from minimum $850 \mathrm{KW}$ to maximum $1600 \mathrm{KW}$ in grid side as well as from diesel generator. This significant power variation creates a situation for an urgent need of power generation reserve and regulation from grid source during ongrid mode of MG operation. Similarly, output power variation of solar PV creates a situation for frequent ramp up and ramp down of power requirement from diesel generator, which will lead to increase in wear and tear effect of conventional power unit components, maintenance cost, and thereby reducing the efficiency of diesel generator.
TABLE IV. RESULTS OF POWER AND VOLTAGE VARIATION

\begin{tabular}{|l|c|}
\hline \multirow{2}{*}{$\begin{array}{c}\text { Effects of Solar } \\
\text { disturbance }\end{array}$} & Simulation Results - 2 \\
\cline { 2 - 2 } Power variation & Minimum $850 \mathrm{KW}$ to maximum $1600 \mathrm{KW}$ \\
\hline Voltage variation & $97.8 \%$ to $98.1 \%$ at LV bus node N7 \\
\hline
\end{tabular}

TABLE V. RESULTS OF THD AND UNBALANCE VOLTAGE LEVEL

\begin{tabular}{|c|c|c|c|c|}
\hline \multirow{2}{*}{$\begin{array}{l}\text { Standard } \\
\text { Limit }\end{array}$} & \multicolumn{4}{|c|}{ Simulation Results - 1} \\
\hline & Node N7 & Node N9 & Node N10 & PV Penetration \\
\hline \multirow{3}{*}{$\begin{array}{c}\text { Current } \\
\text { THD (i) }<5 \%\end{array}$} & $>$ Limit & $>$ Limit & $>$ Limit & $100 \%$ \\
\hline & $>$ Limit & $>$ Limit & $>$ Limit & $70 \%$ \\
\hline & $<$ Limit & $>$ Limit & $>$ Limit & $50-30 \%$ \\
\hline \multirow{3}{*}{\begin{tabular}{l}
\multicolumn{2}{c}{ Voltage } \\
THD (v) $\cong$ \\
$8 \%$
\end{tabular}} & $>$ Limit & $>$ Limit & $>$ Limit & $100 \%$ \\
\hline & $<$ Limit & $<$ Limit & $<$ Limit & $70 \%$ \\
\hline & $<$ Limit & $<$ Limit & $<$ Limit & $50-30 \%$ \\
\hline $\begin{array}{l}\text { Unbalance } \\
\text { Voltage }<3 \%\end{array}$ & \multicolumn{4}{|c|}{ Unbalance voltage level around $1.48 \%$ at node $\mathrm{N} 8$} \\
\hline
\end{tabular}

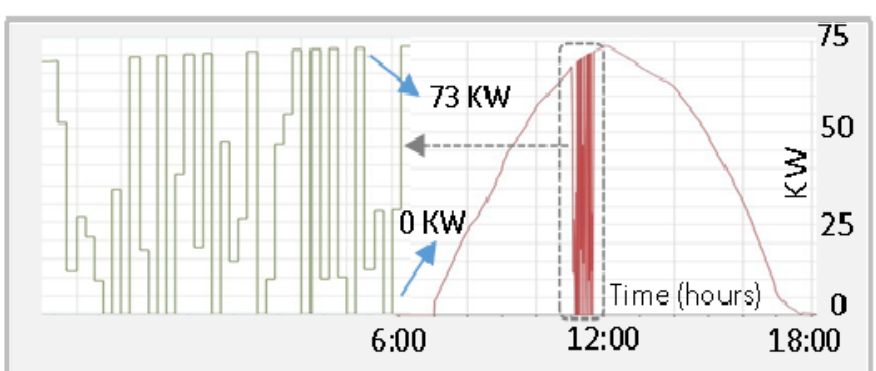

FIGURE IV. PV OUTPUT POWER VARIATION

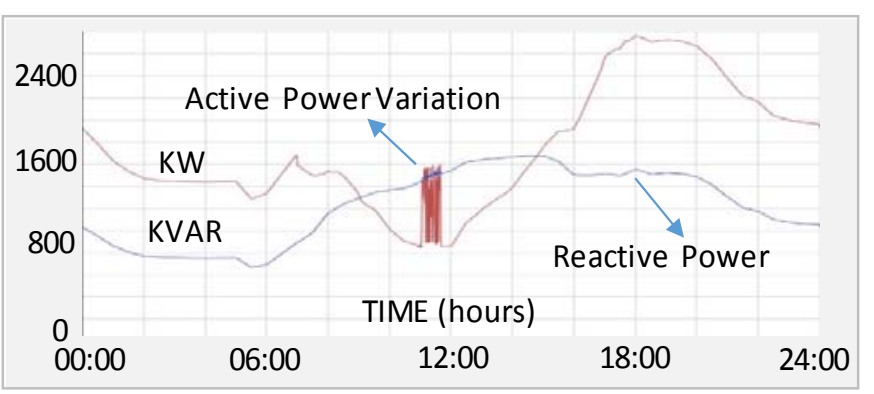

FIGURE V. POWER FLOW VARIATION (GRID / DG)

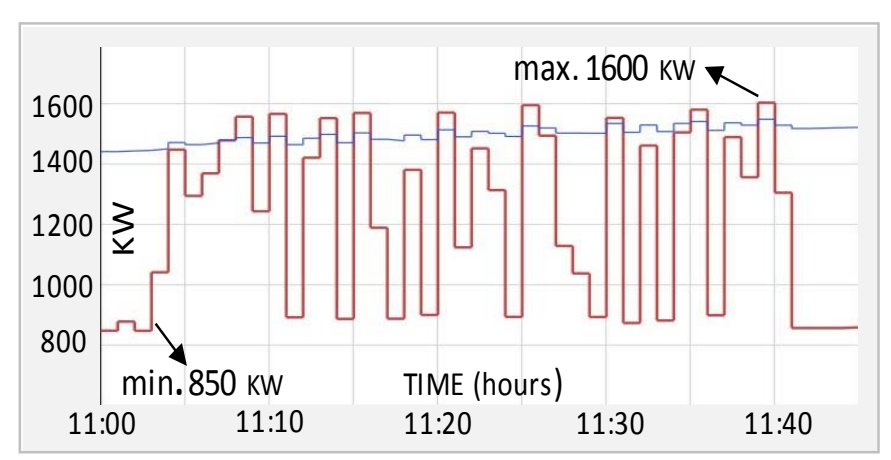

FIGURE VI. POWER VARIATION (GRID / DG) 


\section{B. Voltage Variation}

Variation of output active power disturbs the flow of reactive power causing local variation in voltage level at LV bus node N7. During solar disturbance, a small voltage variation at LV bus node $\mathrm{N} 7$ was observed from minimum $97.8 \%$ to maximum $98.1 \%$ as shown in Figure 7.

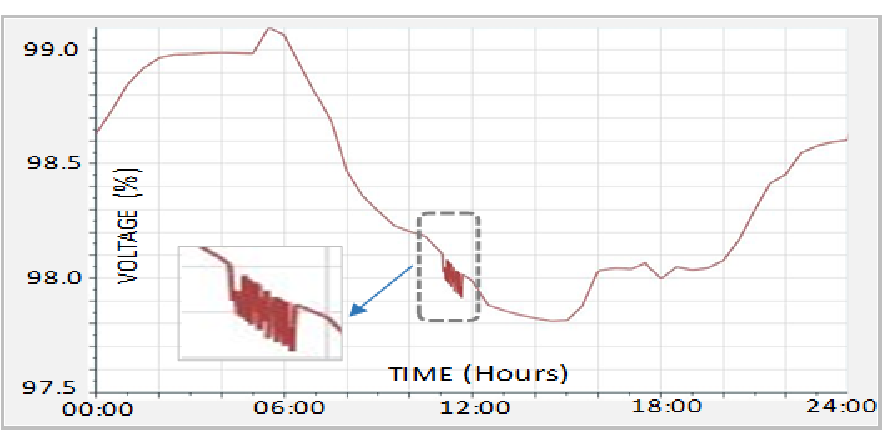

FIGURE VII. VOLTAGE VARIATION AT LV BUS NODE N7

However in case of large level PV integration in a weak network or at peak load with low voltage condition, this voltage variation may reach in a significant level and can affect any sensitive loads connected to that particular bus node.

\section{Harmonic Distortion}

Voltage and current THD in MG network were analysed with $30 \%, 50 \%, 70 \%$, and $100 \%$ of PV penetration in reference to the connected total linear load at LV bus node N7, non-linear load at LV bus node N9, and composite load (linear + non-linear) at LV bus node N10 respectively. As per the AS4777-2005 standard [15], current THD of inverter up to 50 th harmonic order should be less than 5\% and compatibility levels of voltage THD as per AS/NZS 61000 [16] should be around $8 \%$.

Both current and voltage THD level exceeds the standard limit for $100 \%$ PV penetration at LV bus node N7 as shown in Figure 8 . For $70 \%$ of PV penetration level, voltage THD value was within the standard limit, whereas the current THD value exceeds the standard limit. Both the current and voltage THD level were well below the standard limit for $50 \%$ and $30 \%$ of $\mathrm{PV}$ penetration level. From the above results, it is clear that the current and voltage THD gets higher as the level of PV penetration increases. This is due to the cumulative effect of harmonic current injection from PV inverters during higher level of PV generation with reference to full load current of linear load at bus node N7.

As per the THD results at bus node N9 shown in Figure 9, current THD values for all the PV penetration levels were significantly high as compared to bus node N7 and also found to be above the standard limit. In $100 \%$ of PV penetration level, voltage THD were observed just above standard limit $(8.1 \%)$ and within the standard limit for other penetration levels. This is due to the effect of only non-linear load (classA and class-D equipment) connected at bus node N9.

THD results at bus node N10 as shown in Figure 10, clearly indicated that the current THD values were high and above standard limit for all levels of PV penetration $(100 \%$, $70 \%, 50 \%$ and $30 \%$ ) except $20 \%$. Voltage THD values were found to be below the standard limit for all other penetration levels except $100 \%$. Voltage and current THD values at bus node N9 were low as compared to their counterparts at bus node N10. This is due to the effect of composite load where the linear and non-linear loads are distributed in equal $(50 \%)$ proportion at bus node N10. In this study, harmonic filter (passive or active) was not taken into account in the MG network. Only typical current harmonic data for each PV inverter and non-linear load was considered for this THD analysis study.

Based on the results from Figure 8, Figure 9, and Figure 10, it is clear that the THD reaches in significant level in case of higher level of PV penetration, and amount of non-linear load present in the MG network. This high.level of THD can cause power losses, overheating of conductors, transformers, capacitor banks, motors or generators, and excessive current in neutral line etc. [11] in MG network.

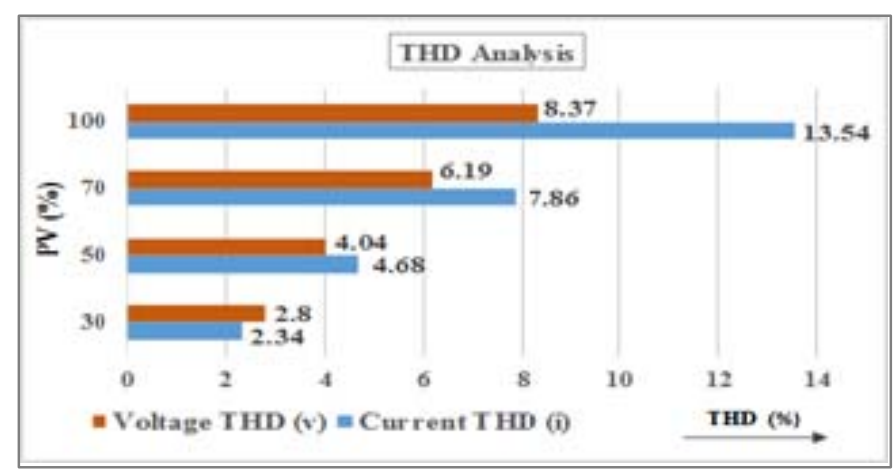

FIGURE VIII. PV WITH LINEAR LOADAT LV BUS NODE N7

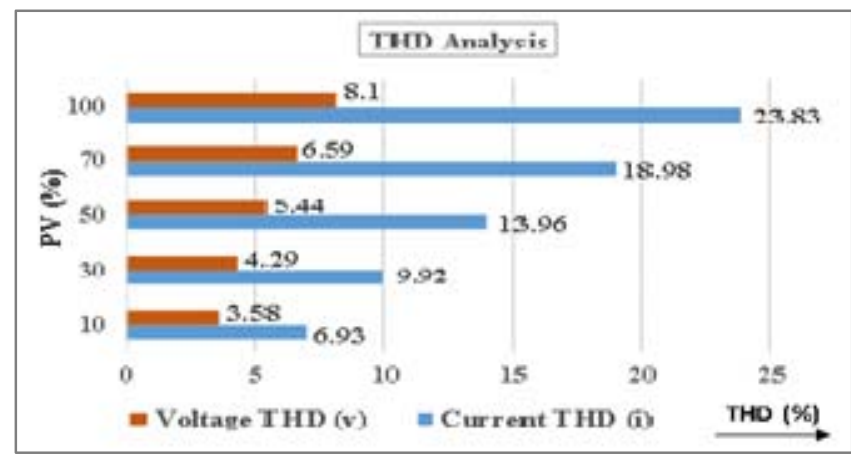

FIGURE IX. PV WITH NON-LINEAR LOAD AT LV BUS NODE N9

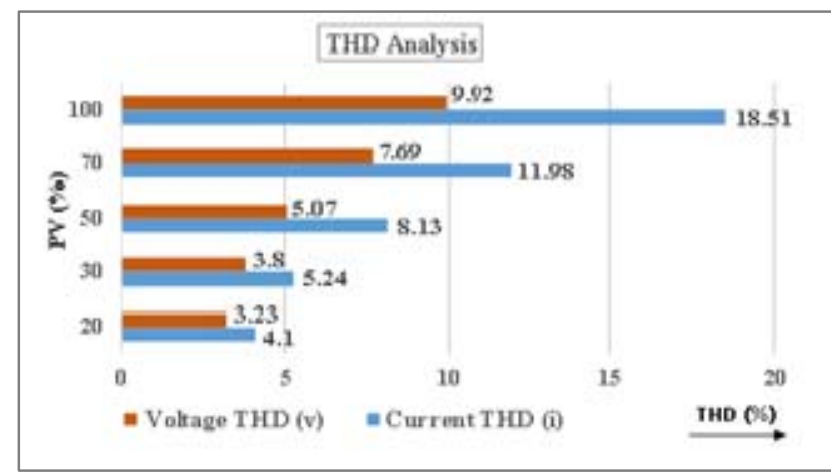

FIGURE X. PV WITH COMPOSITE LOAD AT LV BUS NODE N10 


\section{Voltage Unbalance}

In this study, unbalance voltage level was estimated with typical uneven distribution of single phase loads and single phase PV generators at LV bus node N8. As per the standard AS/NZS 61000.2 [16], compatibility level of unbalance voltage limit in LV network should be less than 3\%. At bus node N8, single phase solar PV and single phase loads were distributed in each phase as follows; $10 \mathrm{KW}$ solar PV and 300 KVA load in phase-A, $100 \mathrm{KW}$ PV and $100 \mathrm{KVA}$ load in phase-B, $200 \mathrm{KW} \mathrm{PV}$ and $10 \mathrm{KVA}$ load in phase-C respectively. According to typical daily load profile, each phase voltage level at bus node N8 are shown in Figure 11. As per the daily voltage profile, it was observed that during peak load period (12:30 hrs), the voltage level difference between phase-A and phase-B, C was more compared to that of low demand period (05:30 hrs). As shown in Figure 12 that the Voltage level in phase-A was low around 96.2\% (399 V), whereas in phase-C was around $99.4 \%(413 \mathrm{~V})$. Through this analysis that the unbalance voltage level at bus node N8 was estimated and found within standard AS/NZS 61000.2 [16] limit of around $1.48 \%$. However, this value may vary according to load condition as per voltage profile shown in Figure 11 and also it can increase further above the standard limit in case of any large LV distribution network with the uneven impedance level, uneven distribution of single phase loads and PV generation in LV network etc. This excessive unbalance voltage can have a significant impact on de-rating of the induction motor with increased heating and losses, increased thermal stress for variable speed drive (VSD) electronic components with the addition of triplen harmonic current etc. [12].

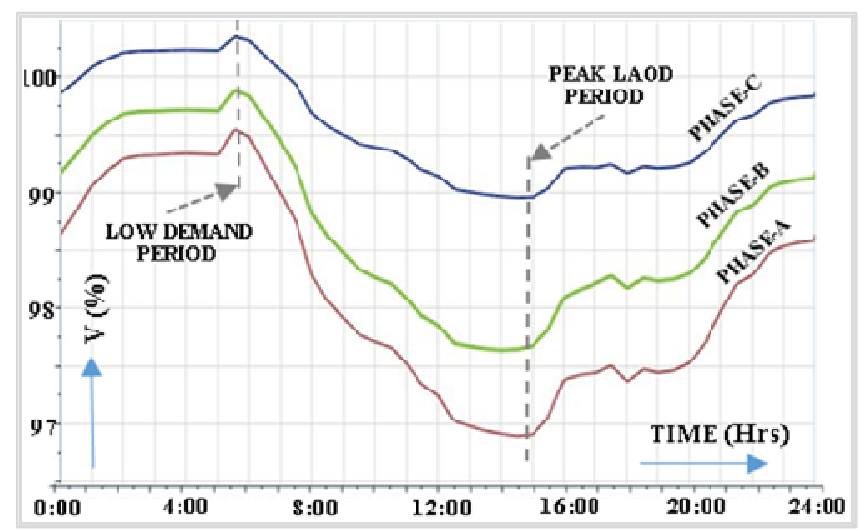

FIGURE XI. UNBALANCE VOLTAGE PROFILE AT BUS NODE N8

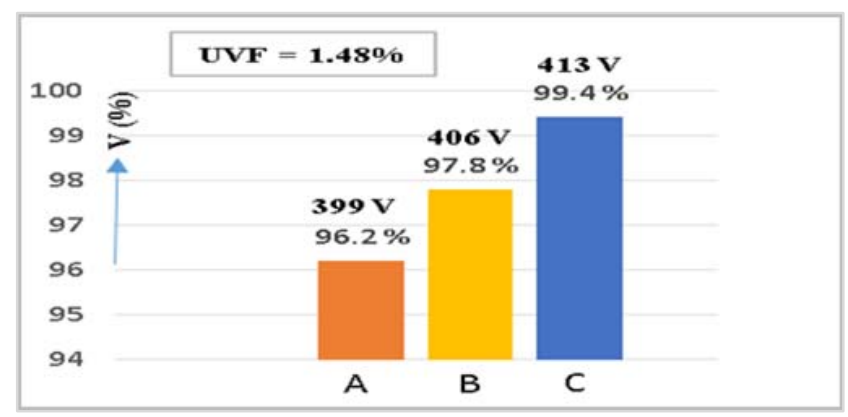

FIGURE XII. UNBALANCE VOLTAGE AT BUS NODE N8

\section{CONCLUSION}

In this paper, PQ issues like power variation, voltage variation, THD, and unbalance voltage level were analysed and quantified through the simulation of typical MG model in PSS-Sincal software environment. These PQ issues arise mainly due to the integration of an intermittent nature of DG sources with PE converter technology and presence of unbalanced / non-linear loads in the MG network. From this simulation results, it can be concluded that the power variation from solar PV output due to solar disturbance causes corresponding effect of power flow variation in both the grid source and diesel generator unit during on-grid as well as offgrid mode of MG operation. PV output power variation also causes local voltage variation at LV bus node N7. Voltage and current THD were observed in an increasing trend with increase of PV penetration levels for all bus nodes N7, N9 and N10. As compared to bus node N7 where linear load connected that the current THD were observed in significant level and found to be above the standard limit at bus node N9 and N10. This is due to the effect of non-linear and composite load connected at bus node N9 and N10 respectively. The unbalance voltage level at $\mathrm{N} 8$ was around $1.48 \%$, this is due to an uneven distribution of the single phase loads and PV generation at bus node N8. Results from this analysis study will be helpful to develop MG model with improved PQ conditions by implementing appropriate control measures in MG network. Considering the findings of this study, future research work for MG model will focus in the following directions;

- Integration of energy storage with implementation of PQ compensating techniques

- Implementation of optimum control and operating strategies

\section{REFERENCES}

[1] N. Hatziargyriou, Microgrids : Architectures and Control: Jhon Wiley \& Sons, 2013.

[2] S. Chowdhury, S. Chowdhury, and P. Crossley, Microgrids and active distribution networks: Institution of Engineering and Technology, 2009.

[3] T. Ackermann, G. Andersson, and L. Söder, "Distributed generation: a definition," Electric power systems research, vol. 57, pp. 195-204, 2001.

[4] W. El-Khattam and M. Salama, "Distributed generation technologies, definitions and benefits," Electric Power Systems Research, vol. 71, pp. 119-128, 2004.

[5] R. Torquato, F. C. Trindade, and W. Freitas, "Analysis of the harmonic distortion impact of photovoltaic generation in Brazilian residential networks," in Harmonics and Quality of Power (ICHQP), 2014 IEEE 16th International Conference on, 2014, pp. 239-243.

[6] M. Farhoodnea, A. Mohamed, H. Shareef, and H. Zayandehroodi, "Power quality impact of renewable energy based generators and electric vehicles on distribution systems," Procedia Technology, vol. 11, pp. 11$17,2013$.

[7] Z. Liu, X. Xu, H. A. Abdelsalam, and E. Makram, "Power System Harmonics Study for Unbalanced Microgrid System with PV Sources and Nonlinear Loads," Journal of Power and Energy Engineering, vol. 3 , p. 43,2015 .

[8] M. Begovic, J. Zhang, D. Novosel, and N. Cho, "Harmonic Distortion in Microgrids and Distribution Systems with Photovoltaic Generators," in System Sciences (HICSS), 2015 48th Hawaii International Conference on, 2015, pp. 2586-2594.

[9] SIMENS. PSS Sincal-Siemens, Power Technologies International-2013. Available: http://www.simtecgmbh.at/sites_en/sincal_information.asp 
[10] EPSMA. Harmonic Current Emissions Standard-61000-3-2,, European Power Supply Manufacturers Association-2010. Available: http://www.epsma.org/pdf/PFC\%20Guide_November\%202010.pdf

[11] D. J. C, Power System Harmonics and Passive Filter Designs: Wiley, 2015.

[12] V.J.Gosbell. Voltage unbalance, Power quality centre, Integral-energy2002. Available: http://www.elec.uow.edu.au/pqaustralia/main/ images /stories/pqrctechnotes/technote6.pdf

[13] V. J. Gosbell, H. Herath, S. Perera, and D. Robinson, "Sources of error in unbalance measurements," 2002.

[14] CSIRO. Solar Intermittency: Australia's Clean Energy Challenge-June2012. Available: https://publications.csiro.au/rpr/download?pid=csiro: EP121914\&dsid=DS1

[15] Standard-Australia. AS 4777.3-2005, Grid connection of energy systemsvia-inverters-2005, Available: http://www.saiglobal.com/pdftemp/ previews/osh/as/as4000/4700/4777.2-2005.pdf

[16] Ausgrid. Network Standard, NS238-Network Supply Quality-2014 Available:http://www.ausgrid.com.au/ /media/Files/Network/Document s/NS\%20and\%20NUS/NS238.pdf 